Athens Journal of Business \& Economics -

Volume 7, Issue 4, October 2021 -Pages 379-394

\title{
The Circular Economy: An Exploratory Case Study from the Paper and Retail Industries
}

\author{
By Peter Jones ${ }^{*} \&$ Daphne Comfort ${ }^{ \pm}$
}

\begin{abstract}
Recent decades have witnessed increasing interest in the concept of the circular economy within both the business world and political circles. The circular economy spans the entire life cycle of products from product design through production, marketing, and consumption, to waste management, recycling, and re-use, and enthusiasm for putting the concept into practice has been identified across different sectors of the economy. This exploratory case study reviews how some of the leading companies in the paper and retail industries, have publicly addressed the circular economy. The case study outlines the nature of the circular economy, provides a cameo literature review of published work on the circular economy, describes the approach adopted for the case study, reports the findings of the review of how the leading companies in the paper and retail industries have addressed the circular economy, and discusses some wider issues.
\end{abstract}

Keywords: circular economy, case study, paper industry, retail industry, greenwash, economic growth

\section{Introduction}

The last decade has witnessed increasing interest in the concept of the circular economy within both the business world and political circles. On the positive side, the "Circular Action Plan" launched by the European Commission (2020) in March 2020 is seen as an essential element in Europe's agenda for sustainable growth, while the Ellen McArthur Foundation (2017a) suggested "a circular economy aims to redefine growth, focusing on positive society-wide benefits". More critically, Gregson et al. (2015), argued that while the concept of the circular economy had received political and commercial support, there was limited evidence of its successful implementation. The circular economy spans the entire life cycle of products from product design through production, marketing, and consumption to waste management, recycling, and re-use, and enthusiasm for putting the concept into practice has been identified across different sectors of the economy.

Within the manufacturing sector, UMP (2020a), one of the world's largest paper producers, argued "pulp and paper are the pioneers of the circular economy", while in the service sector, the European Retail Round Table (2016), the organisation which represents major European retailers, claimed "retailers are a

\footnotetext{
*Associate Professor, School of Business, University of Gloucestershire, UK.

${ }^{ \pm}$Research Associate, School of Business, University of Gloucestershire, UK.
} 
large contributor to the European Union economy" and that retailers "are keen to take a front seat in shaping a circular economy in Europe." With these thoughts in mind, the research objective of this exploratory case study is to review how some of the leading companies in the paper industry (which includes the manufacture of paper, pulp, and packaging) and the retail industry, were publicly addressing the circular economy. More specifically, the case study outlines the nature of the circular economy, provides a cameo literature review of published work on the circular economy, describes the approach adopted for the case study, reports the findings of the review of how the leading companies in the paper and retail industries have addressed the circular economy, and discusses some wider issues.

\section{The Circular Economy}

For the Ellen MacArthur Foundation (2017b), set up in 2010 to help accelerate the transition to a circular economy, a circular economy is a "systemic approach to economic development designed to benefit businesses, society, and the environment". As such, a circular economy is contrasted to the currently dominant take-make-waste linear model of the economy, in that "a circular economy is regenerative by design and aims to gradually decouple growth from the consumption of finite resources". More generally, Lahti et al. (2018) claimed "the idea behind the circular economy is that companies have a responsibility to uphold the environmental and sustainable values of society and must respond to a broad set of stakeholders rather than just their closest shareholders." Geissendoerfer et al. (2017) have suggested that the circular economy is "a new sustainability paradigm".

In theory, the circular economy spans the entire life cycle of products from product design through production, marketing, and consumption to waste management, recycling, and re-use, and enthusiasm for putting the concept into practice the concept, has been identified across different sectors of the economy (e.g. Jones and Comfort 2018a). Design is the first, and in some ways the most important, element in the circular economy. Here the focus is on redesigning products and manufacturing processes around circular economic principles that will increase reuse and recycling, create new business opportunities, and contribute to sustainable economic growth. Essentially, businesses must look to develop their approach to design around new business models that embrace resource efficiency, longevity, and impact. Consumers have a critical role to play in circular economic strategies, not least in that through their buying behaviour they can support or hamper the transition to a circular economy. Within a circular economy, the focus is on recycling waste to recover materials and energy.

\section{Cameo Literature Review}

The concept of the circular economy has attracted a good deal of attention in the academic literature, though Urbinati et al. (2017) suggested that academics 
"within the strategic management field" are "struggling with a lack of a framework explaining how companies willing to become circular adapt their existing business model or create new one". That said, several papers have provided a variety of literature reviews. Merli et al. (2018), for example, provided "a systematic literature review", of over 600 papers and concluded the circular economy is "an evolving concept that still requires development to consolidate its definition, boundaries, principles and associated practices". Masi et al. (2017), offered a systematic literature review, covering 77 articles published since 2005, of the supply chain configurations in the circular economy. Winans et al.'s (2017) literature review, explored "the history of the concept of the circular economy to provide a context for a critical examination of how it is applied currently". Prieto-Sandeval et al. (2018) conducted a literature review that provided "a knowledge map of the circular economy, an analysis of the main notions of the concept, principles, and determinants of a circular economy".

Given these recent accessible reviews of the literature, there sems little point in adding to, or duplicating, these works with a wide-ranging literature on the circular economy. Rather, the authors provide a cameo literature review of three issues that they believe are particularly relevant to this case study, namely greenwashing, the relationship between the circular economy and sustainable consumption and achieving economic growth within a circular economy. The aim here is to provide some simple reference to, and context for, the issues raised in the case study. In examining the use of circular economy case studies in business education, Kopnina (2019) argued "for many companies, rampant greenwashing will not pay as continuous vigilant consumer organizations or NGO's help to move companies beyond the basic requirements of public relations" and that "greenwashing can backfire not only because it has limited benefits, but also because it poses a major threat to business operations if publicly disclosed". More generally, Sauvé et al. (2016) suggested that circular economy initiatives were not immune to greenwashing and that 'because of all the greenwashing that has been associated with the buzzword sustainable development, many proponents of the circular economy approach will avoid references to sustainable development".

Tunn et al. (2019) claimed "combining sustainable consumption with the circular economy concept could help tackle challenges, such as resource scarcity and climate change, by reducing resource throughput and increasing cycling of products and materials within the economic system, thereby reducing emissions and virgin material use". In looking to discover which future business models would help to achieve sustainable consumption in the transition to the circular economy, Tunn et al. (2019) suggested "the most promising business models for sustainable consumption are those that reduce overall consumption levels and consumer effort". In "re-introducing consumption to the circular economy" Mylan et al. (2016) highlighted "the importance of understanding the dynamics of consumption and waste in the domestic sphere" which will involve "a shift from imagining consumers as users of particular products or services, to conceptualisation as doers of everyday activities".

George et al. (2015) presented a "circular economy model of economic growth", which indicated "that the factors affecting economic growth include the 
marginal product of the recyclable input, the recycling ratio, the cost of using the environmentally polluting input and the level of pollution arising from the employment of the polluting input' but their analysis demonstrated that 'environmental quality cannot be maintained or improved via economic growth". Kjaer et al. (2019) focused on decoupling economic growth from resource consumption and concluded that "the ultimate aim of the circular economy should be to enable absolute resource decoupling, which goes beyond simply extracting more value from resources".

\section{Case Study Approach Frame of Reference and Method of Enquiry}

In looking to investigate how some of the leading players within the paper and retail industries were publicly addressing the circular economy, the authors employed a simple case study approach, which the authors believe is appropriate in focussing upon the specific issue of circular economy within the context of two sectors of the economy. This is very much an exploratory case study, in that the focus is on answering simple questions concerning which companies within the paper and retail industries were addressing the circular economy, and the themes they emphasised as part of that process. At the same time, the authors recognise the limitations of their case study approach in that it is based corporate information obtained from the Internet, and thus lacks wider empirical inputs, that it provides limited basis for generalisation. The authors would also stress that the case study looked to review how some of the leading players in the paper and retail industries were addressing the circular economy, rather than to provide a systematic comparative analysis of approaches to the circular economy, within, and between, the two industries.

In looking to focus on how leading players within the paper and retail industries were addressing the circular economy, the authors undertook a threestep Internet search process using Google as the search engine. Firstly, the authors searched the websites of the retail associations in Europe and the US for some contextual information on how Europeans and US retailers were addressing the circular economy. Secondly, the authors undertook an Internet search, using the key phrases Circular Economy and the name of the leading players in the paper and retail industries, drawn up from trade sources, in July 2020 using Google as the search engine. This search of companies in the paper industry revealed that six companies, namely, International Paper, West Rock, UPM, Stora Enso, Sappi and Smurfit Kappa, addressed the circular economy on their corporate websites. The search of leading retailers revealed that six European companies, namely Kingfisher, Ikea, H\&M, Inditex, Marks and Spencer and C\&A, and three US companies, namely Kroger, Home Depot and Walmart, addressed the circular economy on their corporate websites.

Thirdly, the authors then searched the corporate websites of all these fifteen companies to ascertain greater details of how they were addressing the circular economy. The information from this simple content analysis provided the empirical material for this case study, which draws heavily on specific examples 
and selected quotations from the websites of the selected companies within the paper and retail industries. The aim here was to demonstrate how the companies publicly described their commitment to the circular economy and how they were addressing it, and the authors believed that this was often best captured in their own corporate words; not least in that quotations could strengthen the corporate authenticity of the case study.

International Paper is the world's largest producer of paper, pulp, and packaging, it is based in the US, and it has 25,000 commercial customers in 150 countries. West Rock is a US based, paper and corrugated packaging company and it has operations in some 30 countries. UPM, founded in 1996, is headquartered in Finland and it has production facilities in 12 countries. Stora Enso, created in 1998, is also headquartered in Finland and while most of its sales are in Europe, it has operations in Asia, South America, and the US. Sappi is a South African pulp and paper company and it in addition to its African operations, it has production plants in Finland, Germany, Switzerland, and the US. Smurfit Kappa is a paperbased packaging company, headquartered in Ireland, and it operates in 35 countries.

Ikea is an originally Swedish, now a Netherlands headquartered retailer, which sells self-assembly furniture, kitchen appliances and household accessories. Inditex is a Spanish based, multinational clothing retailer and its flagship store brand is Zara. H\&M is a Swedish multinational clothing retailer, and it operates from over 5,000 stores in some 70 countries. Kingfisher is a UK based home improvement retailer, with over 1,200 stores in 10 countries across Europe, Russia and Turkey and it trades as B\&Q, Brico Depot, Screw Fix and Castorama. Marks and Spencer is a British multinational retailer which specialises in clothes, home products and food. C\&A is a Belgian/Dutch/German clothing retailer and it has stores in 19 European countries and a small retail presence in Mexico, South America, and China. Walmart is the world's largest retailer, and it has over 11, 500 stores in 27 countries. Kroger's, operations span 35 US states, and its trading formats include grocery and multi-department stores, convenience outlets and jewellery stores. Home Depot is the largest home improvement retailer in the US, with 2,000 stores, and it also has stores in Canada and Mexico.

\section{The Circular Economy in the Paper Industry}

In many ways, digital technologies have changed the way hundreds of millions of people live their lives, and as such, more and more people may be seen to live in an increasingly digital world, but paper is still important for many economic and social activities. Trade estimates suggests that global paper production was 490 million tonnes in 2020 (Material Trader.com 2019) and the production of paper makes massive demands on trees, water resources and energy supplies. Such high production demands have a major environmental impact, as does the disposal of wastepaper and its industrial by-products, and they pose increasing concerns for sustainable development. The concept of the circular economy offers a way to address these concerns. 
Several of the world's leading paper producers emphasised their strategic commitment to the circular economy. Stora Enso (2019), for example, claimed the circular economy "operates at the heart of the circular bioeconomy". In a similar vein, WestRock (2019) argued "we are proud to play a central role in the circular economy", while Smurfit Kappa (2019) suggested "the circular economy is at the core of our business" and International Paper (2020) claimed it embraced "the concept of the circular economy". Sappi (2019) suggested "at its heart, our business model is circular and interconnected", and UPM (2020b), argued "we see the circular economy as a way to build a sustainable future for both society and business".

Stora Enso (2019) claimed it was in "a unique position to drive society's transition to a circular bioeconomy" and "we always look for ways to make more from less". In taking a broad view, Stora Enso (2019) suggested that "global warming, population growth, urbanisation and eco-awareness were affecting both consumer behaviour and corporate decision making" and claimed "we respond to these trends by developing circular products and solutions based on materials that are both renewable and recyclable". More specifically, Stora Enso (2019) outlined the working of the circular economy in relation to waste and waste management, carbon dioxide emissions, customers, and the United Nations Sustainable Development Goals.

In addressing waste management, Stora Enso reported that it looked to maximise the value of its material streams, and to work towards zero process waste, and that it was working to achieve this through circular material flows in its value chain, while reducing its own process waste to as close to zero as possible. Stora Enso (2019) also claimed "we help our customers become circular". Here the company suggested that as its products are renewable, recyclable, and in many cases compostable, both resource use and waste are minimised and the focus is on maintaining the value and longevity of products and materials, through product design, innovation and recycling. Stora Enso also reported that it had established a circular economy programme to drive circularity in the value chain together with customers, brand owners, and recyclers. This programme focused on circular innovations, industry collaboration to increase the collection and recycling of cardboard products, circular design and co-creation with customers, and work with start-up companies.

UPM (2020b) suggested "the circular economy addresses two key global challenges of our time: climate change and the growing scarcity of natural resources. In a circular economy, waste is minimised, and renewable resources are used in a sustainable, efficient way". The company emphasised that it reused, or recycled, virtually all its production waste, that it and recycled materials and products several times, and looked to create added value through smart solutions, and claimed "our goal is to minimise waste and maximise reuse" (UPM 202b) Under the banner "Circular economy in action" UPM (2020b) provided illustrative examples of how many of its products are made from residues, side steams, and waste generated during its traditional production processes. These examples included, renewal diesel and naphtha produced from a residue from chemical pulp production, and the production of renewable bio-based plastics. 
International Paper (2020) outlined that its approach to the circular economy involved "looking to evolve the design of our products so that they can enjoy multiple lives through repeated cycles of reuse and recycling. We want to eliminate the very word waste from our vocabulary - everything we use to manufacture our products has the potential to be viewed as a renewable resource". However, International Paper observed that paper is not infinitely recyclable, not least in that the fibres that make up paper shorten each time they are recycled and the company emphasised the need to introduce new timber resources into the manufacturing process. This led the company to look beyond recycling to the whole value chain, and to champion responsible forestry, to put residual materials to good use in the manufacturing process, and to maximise recovery and recycling.

Sappi (2019) recognised "the necessity for a more circular global economy, as we move away from a take, make, dispose, model of production, to a more regenerative economic system aimed at minimising waste and making the most of scarce resources" and suggested "at its heart, our business model is circular and interconnected" and "we continue to find ways to maximise the circular nature of our activities". Sappi (2019) illustrated its approach with a case study entitled "an innovative solution for the circular economy", which focused on packaging in the food industry. Within the food industry, packaging that meets stringent health and safety standards and is recyclable, has long posed a challenge for paper and packaging manufacturers. The company reported that it had worked with consumer brand owners to develop renewable paper-based packaging materials which provided an effective barrier against oxygen, water vapour, grease, aroma and mineral oil, without ensuring food protection and the required shelf life.

In his Chief Executive Officer's introduction to Smurfit Kappa's 2019 Sustainability Report, Tony Smurfit claimed "our product is a vital element in society's supply chains, improves our customers' environmental footprints, and fully supports the circular economy by being renewable, recyclable and biodegradable" (Smurfit Kappa 2019). The company reported that in designing its operations around a circular business model meant looking to maximise resource efficiency, to minimise waste and carbon dioxide emissions, and to supply packaging that avoids waste. Further, Smurfit Kappa claimed that its circular business model means that $75 \%$ of its raw material is recycled fibre and that the company used organic by-products as biofuel, circulated process water as much as possible, and looked to find alternative uses for the paper products items rejected by customers.

In addressing climate change and tackling carbon dioxide emissions, Smurfit Kappa (2019) reported "the circular economy is an opportunity for our business as we seek to use resources efficiently, especially in energy production and the creation of innovative packaging solutions". In reporting on its approach to waste, Smurfit Kappa (2019) emphasised its belief that "the circular economy is the business model for the future", with its focus on optimising resource use and minimising waste. The company also reported on how the circular economy impacted on its host communities. Smurfit Kappa illustrated these impacts with several examples, including district heating systems to householders in Pitea, in 
Sweden, supporting municipal water treatment in Nettingsdorf, in Austria and Nervion, in Spain, and collecting recovered paper in Malaga, in Spain.

\section{The Circular Economy in the Retail Industry}

The circular economy has also attracted attention within the retail industry. The European Retail Round Table (2016), for example, argued that "transitioning to a circular economy will allow us to reduce our dependency on virgin materials and improve our exposure to volatile commodity prices". More specifically, Eurocommence and the European Retail Round Table (2018) and Jones and Comfort 2018b) reported that European retailers were taking several steps to introduce the circular economy into their businesses. These steps included greater emphasis on sustainable sourcing, the use of recycled and recyclable materials, the removal of damaging chemicals from production processes and increasing the amount of energy from renewable sources.

Several leading European retailers reported on how they have addressed the circular economy. Kingfisher for example, claimed to be integrating circular economic principles into product design, which will increase their longevity and ultimately protect natural resources for future generations. Further, Kingfisher (2019) reported "our target is to have 20 product ranges or services that help customers and our business get more from less, reuse, or use longer by 2025 ". Kingfisher (2019) also identified its "principles for circular product design", which included materials that are easily and widely recycled, design for durability, low energy and carbon usage and working conditions in the supply chain.

H\&M (2019) reported "our ambition is to become a fully circular business within our entire value chain. This means we move from a linear model - take, use, waste - to a circular model where we maximise resource use and reuse, and where nothing is wasted. This circular strategy applies to our products, as well as to our noncommercial goods such as packaging and items used in store interiors, offices, and other buildings". More specifically H\&M (2020) reported "our brands offer customers a variety of fashion, design and services that enable people to be inspired and to express their own personal style, making it easier to live in a more circular way" and claimed "innovation drives our circularity efforts" in that "we're rethinking how products are made and used, and then reused" and "we are developing new ways to repair, repurpose and recycle goods wherever possible and encouraging our customers to join us on this journey".

Ikea (2020) reported "our ambition is to see all Ikea products as raw materials for the future, and to design them all to have circular capabilities that help to prolong their lives. We will extend our relationship with customers throughout a product's use and end-of-life to enable them to repair, reuse, resell and recycle Ikea products. We will provide and promote services, solutions, and knowledge for circular and sustainable consumption, such as furniture takeback services". Further, Ikea (2020) claimed "transitioning to a circular business affects every part of our value chain, including how we design our products. Circular products will be designed from the very beginning to be reused, refurbished, remanufactured, 
and recycled - extending their lifespan for as long as possible. They will also be material banks for the future, meaning we can take them apart when they are no longer working or wanted and reuse the raw materials".

C\&A (2018) argued "sustainability means rethinking how we design our products for their next use" and "making products that are made with their next use in mind and where we no longer talk about end of life, but rather end of use. This is the philosophy of circular fashion" and "for the apparel sector to become truly circular, each part of the value chain must evolve". The company argued that it had developed a three-point strategy to address the implementation of a circular model. Firstly, by creating innovative products designed according to circular principles, secondly by developing its garment collection scheme to ensure that garments can be collected, sorted and eventually recycled, and thirdly by supporting partnerships to accelerate to accelerate the transition to a circular economy and by supporting innovations designed to enable and enhance circularity.

Inditex claimed that the circular economy was one of two core axis of the company's sustainability strategy. More specifically, Inditex (2019) reported that its "commitment to circularity" was essential in contributing to the de-carbonisation of its value chain, in preparing for the recycling of fabrics, and in transforming the concept of waste so it is increasingly seen as a valuable resource. Marks and Spencer (2020) emphasised "the need to transition to a circular economy where the value of the materials and energy used in products are kept for as long as possible', and in outlining its approach to waste, the company claimed 'we support the transition to a sustainable circular economy and will prioritise business model innovation and put circular ways of working into practice".

Amongst retailers in the US, there seems to be less public enthusiasm for the concept of the circular economy. The Retail Industry Leaders Association (2020a) recognised that "the retail industry has an important role to play in creating a more circular economy". In addressing "environmental sustainability", for example, the Retail Industry Leaders Association (2020b), claimed "our priorities are increasing efficiency and waste diversion and exploring circular economy innovations for waste" but there was no presentation of how this priority was to be pursued. In a similar vein, some of the largest US retailers publicly reported on the circular economy in relation to parts of their overall retail operations but fell short of making any wide-ranging corporate commitments. Kroger (2019), for example, reported "in 2018, we used more than 160 million reusable plastic containers to ship produce in our distribution network, reducing waste and moving us toward more circular models", and that its distribution centres "champion our circular economy initiatives through their deployment of reusable shipping pallets and reusable plastic containers". Home Depot (2019) reported that the circular economy was one of the sustainability issues that informed its materiality assessment framework and claimed, "we will embrace circular economy products and packaging as suppliers continue to develop their thinking and capabilities". More extensively, Walmart (2019) reported "increasing global demand is placing unsustainable pressure on the climate and natural ecosystems, challenging us all to shift from a take-make-dispose system of production and consumption to a circular, regenerative approach". 


\section{Discussion}

This case study revealed how some of the leading companies within the paper and retail industries have addressed the concept of the circular economy, but three wider sets of issues merit discussion. Firstly, there are issues about the concept of the circular economy meaning different things to different players. Corvellec et al. (2020) acknowledged that the circular economy "allows for a whole range of interpretations and approaches to be bundled together". As such, this effectively allows companies to define the circular economy to mean what they want it to mean. This raises the spectre of greenwashing, typically described as "communication that misleads people into forming overly positive beliefs about an organization's environmental practices or products" (Lyon and Montgomery 2015). So seen, corporate commitments to the circular economy might be characterised by what Hamilton (2009) described as "shifting consciousness" towards "what is best described as green consumerism". This he saw as "an approach that threatens to entrench the very attitudes and behaviours that are antithetical to sustainability".

All companies who publicly proclaimed their commitment to the circular economy will need to avoid their commitments and achievements being labelled as greenwash, not least in that such accusations will damage not only the trust between companies and their customers, but it may also reduce the appeal of companies to investors. The European Commission's (2020) new Circular Economy Action Plan, mentioned earlier, suggested "the Commission will also consider further strengthening consumer protection against green washing". However, there was no indication for the time scale for such strengthening, or of what form it might take, or if it might affect manufacturing industry. Ideally, companies should look to take responsibility for reporting on their contributions to a transition a more circular economy, and here a way forward would be for companies to include their achievements in their annual reports or their annual sustainability reports. However, in the past, research suggested that independent external assurance of much of the data in sustainability reports, in both the paper industry (e.g. Jones and Comfort 2017) and retail industry (e.g. Jones et al. 2011) was at best limited. This would, in turn, emphasise the importance of all companies commissioning comprehensive, independent external assurance to verify their contributions to the circular economy.

Secondly, the transition to a circular economy would certainly constitute a dramatic change in the ways in which consumers approach consumption and see the emergence of a "new consumption culture" (Korhonen et al. 2018) with consumers sharing, and leasing, rather than buying, goods and services, and with the emphasis being on collective rather than individual consumer behaviour. The emergence of such a culture would also challenge the social value which consumers often place on the acquisition of goods as part of a process of conspicuous consumption. At the same time, it remains to be seen how enthusiastically consumers, who have been at the heart of materialist culture, in what is often termed the throwaway society, will want to embrace such a new consumption culture. 
Any transition to a circular economy is also intimately bound up with the elusive issue of sustainable consumption, described by Cohen (2005) as "the most obdurate challenge for the sustainable development agenda". GreenBiz (2015) argued "entrenched patterns of overconsumption present a massive hurdle to clear before circular economic models can achieve any sort of scale". In many ways, what some commentators see as the continuing and unrestrained pursuit of unsustainable consumption, described by the European Environment Agency (2019) as the "mother of all environmental issues", lies close to the heart of this dilemma. Korhonen et al. (2018), for example, suggested that "the most important question for the circular economy in terms of long-term sustainable development of global society, is how can the saved resources and money generated by the circular economy idea be directed to sustainable consumption practices".

Thirdly, the transition to a circular economy raises issues about traditional business models, and more fundamentally about existing economic and political structures. Such transformations would certainly challenge traditional business models. The dominant traditional business model within large scale European and North American retailing, for example, revolves around price, sourcing across wide international geographical areas, looking to extensive marketing and advertising to stimulate consumer demand and enhancing access and convenience. The transition to a circular economy could see the growth of a larger service economy, with a greater accent on consumers leasing products, as and when they are required, rather than on purchasing and owning products. How well traditional retailers could meet the challenges posed by such changes remains very much to be seen.

At the same time, there are more contentious, issues about the relationship between the transition to, a circular economy, and existing economic and political structures. Gregson et al. (2015), for example, argued that a circular economy "would require radical transformations to the economic order, including fundamental recasting of manufacture, retail, consumption and property rights". How such changes might be played out, and how they might be resisted is a thorny issue. Concerns have been expressed that the concept of the circular economy might be captured by corporate interests, and more specifically by corporate capitalism. Valenzuela and Bohm (2017), for example, argued, that the terms circular economy and sustainability were effectively being "captured by politiceconomic elites claiming that rapid economic growth can be achieved in a way that manages to remain responsible to environment and society".

\section{Conclusion}

This case study reveals the ways in which some large companies within the paper and retail industries have addressed the concept of the circular economy. While the authors' approach is applicable in principle, to small and medium sized companies, it can only be applied to such companies if they address the issue of the circular economy on their corporate websites. Nevertheless, the case study is valuable in that it provides illustrations of approaches to the circular economy 
from contrasting stages of the product life cycle, the one focussed on manufacturing and the other on retailers. In both sets of industries, companies varied in the extent of their commitment to the circular economy, though such commitment was arguably stronger from the manufacturing companies, but many corporate commitments were, at least partly, aspirational. That said, companies in both sets of industries evidenced their commitment with several practical illustrations of the circular economy in action. Many of these illustrations of the workings of the circular economy were of waste management initiatives, and while waste management is an essential part of the transition to a circular economy, it is but one element in the product life cycle. However, all companies might, at best, be seen to be just embarking on long circular economy journey and they may encounter many challenges, often outside their control, along the way.

While this case study has its limitations, as outlined earlier, the authors believe it offers an appropriate exploratory review of how some leading companies in the paper and retail industries are addressing the circular economy, and as such it provides a platform for future research. Such research might include investigations of corporate thinking, and policy development, on the circular economy, and the forces driving the pursuit of circular economy business models; of if, and how, stakeholders' concerns are incorporated into circular economy strategies and policies; of how corporate policies towards the circular economy are communicated to employees, customers and suppliers; and of how data on circular economy achievements is collected, and of how such data is independently verified. Such research endeavours could include comparative investigations of companies throughout the supply chain and detailed case studies of specific companies. The nature of the information on the circular economy posted by the companies in the paper and retail industries, and the small number of companies included in the current case study, does not allow an analysis of the impact of the circular economy on costs, efficiency and productivity, but these issues will certainly provide important future research agendas. At the same time, researchers may look to explore if there are geographical variations in corporate approaches to the circular economy, for example between European and North American companies, and if company size is a factor in the adoption of circular principles

\section{References}

C\&A (2018) Circular fashion. Retrieved from: http://sustainability.c-and-a.com/uk/en/su stainability-report/2018/sustainable-products/circular-fashion/. [Accessed 14 July 2020.]

Cohen MJ (2005) Sustainable consumption in national context; an introduction to the symposium. Sustainability, Science Practice and Policy 1(1): 22-28.

Corvellec H, Bohm S, Stowell A, Valenzuela F (2020) Introduction to the special issue on the contested realities of the circular economy. Culture and Organisation 26(2): $97-$ 102.

Ellen McArthur Foundation (2017a) What is a circular economy. Retrieved from: https://www.ellenmacarthurfoundation.org/circular-economy/concept. [Accessed 20 July 2020.] 
Ellen McArthur Foundation (2017b) The circular economy in detail. Retrieved from: https://www.ellenmacarthurfoundation.org/explore/the-circular-economy-in-detail. [Accessed 21 July 2020.]

Eurocommence and the European Retail Round Table (2018) Circular Economy Agreement. Retrieved from https://ec.europa.eu/environment/industry/retail/pdf/REAP\%20Circu lar\%20Economy\%20Agreement.pdf. [Accessed 5 July 2020.]

European Commission (2020) A new circular economy action plan. Retrieved from: https: //bit.ly/2GTpKgy. [Accessed 4 July 2020.]

European Environment Agency (2019) Unsustainable consumption-the mother of all environmental issues. Retrieved from: https://www.eea.europa.eu/highlights/unsustai nable-consumption-2013-the-mother. [Accessed 26 November 2017.]

European Retail Round Table (2016) How to make the circular economy happen retailers' approach. Retrieved from: http://www.errt.org/content/how-make-circulareconomy-happen-\%E2\%80\%93-retailers\%E2\%80\%99-approach. [Accessed 13 November 2017.]

Geissendoerfer M, Savaget P, Bocken NMP, Hultink EJ (2017) The circular economy - A new sustainability paradigm. Journal of Cleaner Production 143(Feb): 757-768.

George DAR, Lin BC, Chen Y (2015) A circular economy model of economic growth. Environmental Modelling and Software 73(Nov): 60-63.

GreenBiz (2015) Defining the circular economy. Retrieved from: https://www.greenbiz. com/article/defining-circular-economy-beyond-recycling-material-reuse. [Accessed 14 November 2017.]

Gregson N, Crang M, Fuller S, Holmes H (2015) Interrogating the circular economy: the moral economy of resource efficiency in the EU. Economy and Society 42(2): 218243.

H\&M (2019) Sustainability performance report 2019. Retrieved from: https://sustaina bilityreport.hmgroup.com/wp-content/uploads/2020/04/HM-Group-SustainabilityPerformance-Report-2019.pdf. [Accessed 5 July 2020.]

Hamilton C (2009) Consumerism, self-creation and prospects for a new ecological consciousness. Journal of Cleaner Production 18(6): 571-575.

Home Depot (2019) Circular economy. Retrieved from: https://ecooptions.homedepot. com/circular-economy/. [Accessed 5 July 2020.]

Ikea (2020) Sustainability report. Retrieved from: https://preview.thenewsmarket.com/Pre views/IKEA/DocumentAssets/535135.pdf. [Accessed 5 July 2020.]

Inditex (2019) Annual report. Retrieved from: https://www.inditex.com/documents/10279 /645708/2019+Inditex+Annual+Report.pdf/688d1a9a-ad63-a4d6-8b16cf64d8f91fba. [Accessed 5 July 2020.]

International Paper (2020) Recycling and beyond. Retrieved from: https://renewablefuture. internationalpaper.com/recycling-and-beyond/. [Accessed 14 July 2020.]

Jones P, Hillier D, Comfort D (2011) Sustainability in the global shop window. International Journal of Retail and Distribution Management 39(4): 256-271.

Jones P, Comfort D (2017) The forest, paper and packaging industry and sustainability. International Journal of Sales, Retailing and Marketing 6(1): 3-21.

Jones P, Comfort D (2018a) The circular economy and the construction industry. International Journal of Management Cases 20(1): 4-15.

Jones P, Comfort D (2018b) The circular economy and the leading European retailers: a research note. European Journal of Sustainable Development Research 2(2): 1-8.

Kingfisher (2019) Sustainability report 2018/19. Retrieved from: https://www.kingfisher. com/sustainability-highlights/Kingfisher_Sustainability_Report_2018_19.pdf.

[Accessed 5 July 2020.] 
Kjaer LL, Pigosso DCA, Niero M, Bech NM, McAloone TC (2019) Product/ service systems for a circular economy: the route to decoupling economic growth to resource consumption. Journal of Industrial Ecology 23(1): 22-35.

Kopnina H (2019) Green-washing or best case practices? Using circular economy and cradle to cradle case studies in business education. Journal of Cleaner Production 239(Feb): 613-621.

Korhonen J, Honkasalo A, Seppala J (2018) Circular economy: the concept and its limitations. Ecological Economics 143(Jan): 37-46.

Kroger (2019) A sustainable future. Retrieved from: http://sustainability.kroger.com/Kro ger-2019-ESG-Report.pdf. [Accessed 5 July 2020.]

Lahti T, Wincent J, Parida V (2018) A definition and review of the circular economy, value creation and sustainable business models: where are we now and where should we move in the future. Sustainability 10(8): 2799.

Lyon TP, Montgomery AW (2015) The means and ends of greenwash. Organization and Environment 28(2): 223-249.

Marks and Spencer (2020) Waste and circular economy. Retrieved from: https://corpo rate.marksandspencer.com/sustainability/business-wide/waste-and-circular-economy. [Accessed 6 July 2020.]

Masi D, Day S, Godsell J (2017) Supply chain configurations in the circular economy: a systematic literature review. Sustainability 9(9): 1602.

Material Trader.com (2019) The complete guide to a circular economy of paper. Retrieved from: https://community.materialtrader.com/the-complete-guide-to-a-circular-econo my-of-paper/. [Accessed 13 July 2020.]

Merli R, Preziosi M, Acampora A (2018) How do scholars approach the circular economy? A systematic literature review. Journal of Cleaner Production 178(Mar): 703-722.

Mylan J, Holmes H, Paddock J (2016) Re-Introducing consumption to the circular economy: a sociotechnical analysis of food provisioning. Sustainability 8(8): 1-14.

Prieto-Sandeval V, Jaca C, Ormazabal M (2018) Towards a consensus on the circular economy. Journal of Cleaner Production 179(Apr): 605-615.

Retail Industry Leaders Association (2020a) Retailers find innovation key to circular economy. Retrieved from: https://www.rila.org/blog/2019/07/retailers-find-innova tion -key-to-circular-economy. [Accessed 5 July 2020.]

Retail Industry Leaders Association (2020b) Sustainability/environment. Retrieved from: https://www.rila.org/focus-areas/sustainability-environment. [Accessed 5 July 2020.]

Sappi (2019) Group sustainability report 2019. Retrieved from: https://cdn-s3.sappi. com/s3fs-public/2019-Sappi-Group-Sustainability-Report_v5.pdf. [Accessed 14 July 2020.]

Sauvé S, Bernard S, Sloan P (2016) Environmental sciences, sustainable development and circular economy: alternative concepts for trans-disciplinary research. Environmental Development 17(Jan): 48-56.

Smurfit Cappa (2019) Delivering a better tomorrow: sustainable development report 2019. Retrieved from: file:///C:/Users/Asua/AppData/Local/Packages/Microsoft.Mic rosoftEdge_8wekyb3d8bbwe/TempState/Downloads/Smurfit_Kappa_Sustainable_D evelopment_Report_2019\%20(1).pdf. [Accessed 14 July 2020.]

Stora Enso (2019) Sustainability: part of Stora Enso's annual report 2019. Retrieved from: https://www.storaenso.com/-/media/documents/download-center/documents/an nual-reports/2019/storaenso_sustainability_2019.pdf?la=en. [Accessed 13 July 2020.]

Tunn VSC, Bocken MP, van den Hende EA, Schoomans JPL (2019) Business models for sustainable consumption in the circular economy: an expert study. Journal of Cleaner Production 12(2): 324-333. 
UMP (2020a) Pulp and paper are the pioneers of the circular economy. Retrieved from: https://www.upmpulp.com/media/blogs-and-stories/stories/pulp-and-paper-are-thepioneers-of-the-circular-economy/. [Accessed 13 July 2020.]

UMP (2020b) The shape of the future is circular. Retrieved from: https://www.upm.com/ responsibility/circulareconomy/. [Accessed 13 July 2020.]

Urbinati A, Chiaroni D, Chiesa V (2017) Towards a new taxonomy of circular economy business models. Journal of Cleaner Production 168(Dec): 487-498.

Valenzuela F, Bohm S (2017) Against wasted politics: a critique of the circular economy. Ephemera: Theory and Politics in Organization 17(1): 23-60.

Walmart (2019) 2019 Environmental, social and governance report. Retrieved from: https://corporate.walmart.com/media-library/document/2019-environmental-socialgovernance-report/_proxyDocument?id=0000016c-20b5-d46a-afff-f5bdafd30000. [Accessed 5 July 2020.]

Westrock (2019) 2019 GRI report. Retrieved from: https://www.westrock.com/-/media/ pdf/sustainability/westrock-2019-gri-report-pdf.pdf?modified=20200601161548. [Accessed 13 July 2020.]

Winans K, Kendall A, Deng H (2017) The history and current applications of the circular economy concept. Renewable and Sustainable Energy Reviews 68(1): 825-833. 
